\title{
Obstructive Sleep Apnea Syndrome Causes Vascular Dysfunction, Similarly with Diabetes Mellitus
}

\author{
Raluca-Ileana Mincuㅜㄹ, Andrea Ciobanu ${ }^{1,2}$, Tudor Constantinescu ${ }^{3}$, Stefan Dumitrache Rujinski ${ }^{3}$, Sorina \\ Mihaila $^{1,2}$, Dragos Vinereanu ${ }^{1,2}$ and Lucia-Stefania Magda ${ }^{1,2 *}$ \\ ${ }^{1}$ Cardiac Research Unit University and Emergency Hospital, Romania \\ ${ }^{2}$ University of Medicine and Pharmacy "Carol Davila", Romania \\ 3"Marius Nasta" Institute of Pneumology, Romania \\ Submission: February 22, 2019; Published: March 14, 2019 \\ *Corresponding author: Lucia-Stefania Magda, University and Emergency Hospital Bucharest, Cardiac Research Unit, Splaiul Independentei \\ Street 169050098, Bucharest, Romania
}

\begin{abstract}
Background: The mechanisms of cardiovascular adverse events in Obstructive Sleep Apnea Syndrome (OSAS) are not fully clarified, but vascular dysfunction plays a key role. However, the protocols for assessing vascular function are heterogenous and there are new vascular function parameters that could emerge into practice.

Methods: The vascular function was assessed through Intima Media-Thickness (IMT), "e-tracking" and "wave intensity" technologies in 60 subjects ( $55 \pm 12$ years, 9 women): 20 patients with moderate to severe OSAS (mean apnea-hypopnea index $43 \pm 23$ ) without diabetes; 20 patients with type 2 Diabetes Mellitus (DM), and 20 control, normal subjects (C), age, gender and cardiovascular risk factors matched.

Results: IMT in OSAS and DM groups were similar, but statistically higher compared to C group. Arterial stiffness parameters, like Peterson's pressure-strain elastic modulus (Ep), beta stiffness index ( $\beta$ ), Arterial Compliance (AC), First Systolic Peak (FP), and second Systolic Peak (SP) were similar between OSAS and DM group, but significantly affected compared to C group. Endothelial dysfunction quantified through Flow Mediated Dilation (FMD) was similar in the OSAS and DM groups and statistically significant lower compared to control group.

Conclusion: Patients with moderate to severe OSAS have increased vascular remodeling, vascular stiffness and endothelial dysfunction, with similar vascular profile with patients with DM, suggesting that OSAS should be considered a disease associated with a high cardiovascular risk.

Keywords: Obstructive sleep apnea; Diabetes mellitus; Arterial stiffness; Endothelial dysfunction

Abbrevations: OSAS: Obstructive Sleep Apnea Syndrome; IMT: Intima Media-Thickness; DM: Diabetes Mellitus; AC: Arterial Compliance; SP: Systolic Peak; FMD: Flow Mediated Dilation; PWV: Pulsed Wave Velocity; PP: Pulse Pressure; Aix: Augmentation Index
\end{abstract}

\section{Introduction}

Obstructive Sleep Apnea Syndrome (OSAS) is an independent risk factor for cardiovascular disease, associated with high morbidity and mortality [1,2]. The mechanisms of cardiovascular disease in OSAS are not fully elucidated, but vascular dysfunction plays a key role.

Studies performed in the last decade used especially IntimaMedia Thickness (IMT), Pulsed Wave Velocity (PWV) and Pulse Pressure (PP) as main parameters to diagnose the arterial remodeling and stiffness, whereas extensive protocols could bring a better insight into the pathology [3-6]. The current literature data provides heterogenous data regarding the assessing the vascular function, therefore an extension of the vascular function protocol with parameters of clinical importance could improve the management of patients with early stages of atherosclerosis.
We applied a complex arterial function protocol to a group of patients with OSAS, and we compared the outcomes with a group of patients with type 2 Diabetes Mellitus (DM) and to a group of matched control subjects. We have chosen a group of patients with DM in order to emphasize the fact that OSAS is not a benign disease, but a modifiable risk factor for cardiovascular disease, comparable with DM.

\section{Methods}

\section{Study population}

We assessed the arterial function in three different groups: a group of 20 patients diagnosed with moderate-severe OSAS, a group of 20 patients with well controlled type $2 \mathrm{DM}$ and a group of normal subjects, age, gender, and risk factors matched. The 
study protocol was approved by the Local Ethic Committee and all subjects gave their written informed consent.

\section{Arterial function}

The arterial function assessment protocol was complex, focused on the vascular remodeling, vascular stiffness and endothelial function. The evaluation was made using the Aloka Prosound $\alpha 10$ ultrasound machine (Japan), with a $7.5 \mathrm{MHz}$ linear array probe.

Intima-Media Thickness (IMT) was measured at the right common carotid artery, $1 \mathrm{~cm}$ below bifurcation, according to the current guidelines [7].

The arterial stiffness was analyzed at the level of right common carotid artery, using the high-resolution online tracking wall ("E-tracking") technology to determine Peterson's pressurestrain elastic modulus (Ep), beta stiffness index ( $\beta$ ), the local Arterial Compliance (AC) and the Augmentation Index (Aix) and the "wave intensity" real-time analysis to determine the First Peak (FP), Second Peak (SP) and the Negative Area (NA), as previously reported [8,9]. Endothelial function was analyzed by Flow Mediated Dilation (FMD) on the right brachial artery [10].

The reproducibility and repeatability of all echographic parameters were measured in our laboratory in 20 consecutive patients by two observers with similar experience, with good intra- and interobserver variability [10].

\section{Results}

60 patients were studied, with the mean age of $55 \pm 12$ years, 9 women: 20 patients with moderate-severe obstructive sleep apnea, with an AHI of $43 \pm 23,20$ patients with DM, and 20 control subjects, similar as age, gender and risk factors. The general characteristics of the patients are presented in Table 1.

Table 1: The general characteristics of the study groups.

\begin{tabular}{|c|c|c|c|c|}
\hline Study group & $\begin{array}{c}\text { OSAS } \\
(\mathbf{n}=\mathbf{2 0})\end{array}$ & $\begin{array}{c}\text { DM } \\
(\mathbf{n}=\mathbf{2 0})\end{array}$ & $\begin{array}{c}\text { Control } \\
(\mathbf{n}=\mathbf{2 0})\end{array}$ & p value \\
\hline Age (years) & $55 \pm 11$ & $59 \pm 9$ & $51 \pm 15$ & NS \\
\hline
\end{tabular}

\begin{tabular}{|c|c|c|c|c|}
\hline $\begin{array}{c}\text { Gender (\% } \\
\text { male) }\end{array}$ & 90 & 90 & 75 & NS \\
\hline $\begin{array}{c}\text { Body mass } \\
\text { index (kg/m²) }\end{array}$ & $36.2 \pm 5.6$ & $30 \pm 4.3$ & $26.7 \pm 2.8$ & NS \\
\hline Waist-hip ratio & $0.91 \pm 0.22$ & $0.83 \pm 0.2$ & $0.78 \pm 0.31$ & NS \\
\hline NYHA class & $\mathrm{I}$ & $\mathrm{I}$ & $\mathrm{I}$ & $\mathrm{NS}$ \\
\hline $\begin{array}{c}\text { Systolic arte- } \\
\text { rial pressure } \\
\text { (mmHg) }\end{array}$ & $138 \pm 21$ & $141 \pm 13$ & $124 \pm 16$ & $\mathrm{NS}$ \\
\hline $\begin{array}{c}\text { Diastolic arte- } \\
\text { rial pressure } \\
\text { (mmHg) }\end{array}$ & $79 \pm 13$ & $89 \pm 6$ & $76 \pm 13$ & $\mathrm{NS}$ \\
\hline $\begin{array}{c}\text { Heart rate } \\
\text { (beats/min) }\end{array}$ & $72 \pm 12$ & $71 \pm 9$ & $68 \pm 10$ & $\mathrm{NS}$ \\
\hline $\begin{array}{c}\text { Pulse Prea- } \\
\text { surre (mmHg) }\end{array}$ & $69 \pm 19$ & $52 \pm 11$ & $49 \pm 10$ & $\mathrm{NS}$ \\
\hline
\end{tabular}

\section{Vascular remodeling}

The IMT was statistically significant higher in OSAS and DM group $(0.94 \pm 0.15$ and $0.89 \pm 0.15)$, compared to the control group $(0.64 \pm 0.12$, both $\mathrm{p}<0.01)$, but similar between OSAS and DM groups ( $\mathrm{p}=0.8)$ (Table $2 \&$ Figure 1$)$.

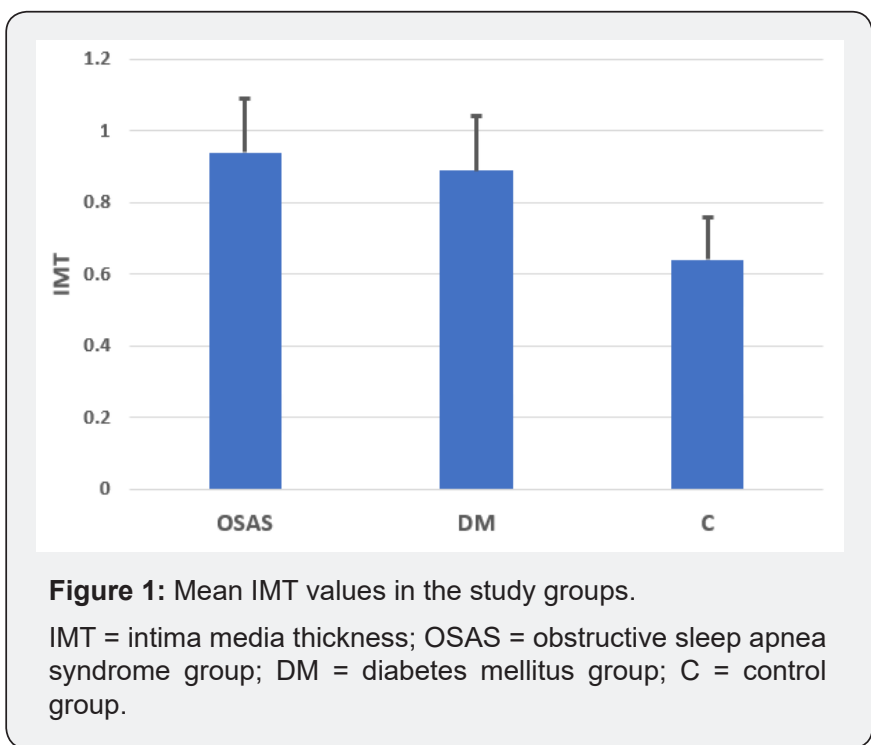

Table 2: The results of vascular function assessment of patients with OSAS and DM, compared to controls.

\begin{tabular}{|c|c|c|c|c|c|c|c|}
\hline & IMT (mm) & Ep (kPa) & Beta index & $\begin{array}{c}\text { AC }\left(\mathrm{cm}^{2}\right) \\
\mathrm{mmHg})\end{array}$ & FP & SP & FMD (\%) \\
\hline OSAS & $0.94 \pm 0.15$ & $129.4 \pm 38.2$ & $10.0 \pm 2.9$ & $0.8 \pm 0.3$ & $8.0 \pm 7.4$ & $1.0 \pm 0.7$ & $7.7 \pm 2.9$ \\
\hline DM & $0.89 \pm 0.15$ & $128.4 \pm 35.5$ & $8.8 \pm 2.4$ & $0.9 \pm 0.5$ & $7.5 \pm 6.6$ & $1.6 \pm 1.0$ & $8.4 \pm 3.5$ \\
\hline Controls & $0.64 \pm 0.12$ & $87.1 \pm 43.3$ & $6.8 \pm 2.6$ & $1.4 \pm 2$ & $9.4 \pm 6.6$ & $0.6 \pm 0.4$ & $19.1 \pm 11.0$ \\
\hline p OSA vs. DM & 0.8 & 0.8 & 0.5 & 0.08 & 0.8 & 0.2 & 0.1 \\
\hline p OSA vs. controls & 0.00 & 0.05 & 0.04 & 0.05 & 0.06 & 0.06 & 0.01 \\
\hline p DM vs. controls & 0.00 & 0.05 & 0.04 & 0.05 & 0.05 & 0.06 & 0.01 \\
\hline
\end{tabular}

$\mathrm{IMT}=$ intima-media thickness; $\mathrm{Ep}=$ Young elastic module; $\mathrm{AC}=$ arterial compliance; $\mathrm{FP}=$ first peak; $\mathrm{SP}=$ second peak; $\mathrm{FMD}=$ flow mediated dilation . Data are expressed as means \pm standard deviation. 


\section{Arterial stiffness}

The parameters of arterial stiffness were statistically significant modified in the OSAS and DM groups $(\mathrm{Ep}=129.4 \pm 38.2$ and $128.4 \pm 35.5$, Beta index $=10.0 \pm 2.9$ and $8.8 \pm 2.4, \mathrm{AC}=0.8 \pm 0.3$ and $0.9 \pm 0.5$ ) compared to the control group ( $\mathrm{Ep}=87.143 .3$, Beta index=6.8 $\pm 2.6, \mathrm{AC}=1.4 \pm 2$ ). The values were similar between OSAS and DM groups (Table 2).

\section{Ventriculo-arterial coupling}

Ventriculo-arterial coupling was borderline affected in OSAS and $\mathrm{DM}$ groups $(\mathrm{FP}=8.0 \pm 7.4$ and $7.5 \pm 6.6, \mathrm{SP}=1.0 \pm 0.7$ and $1.6 \pm 1.0)$ compared to controls ( $\mathrm{FP}=9.4 \pm 6.6, \mathrm{SP}=0.6 \pm 0.4)$, but similarly affected between the group of OSAS and DM patients (Table 2).

\section{Endothelial dysfunction}

Endothelial dysfunction analyzed through FMD was similar in the OSAS and DM groups (FMD=7.7 \pm 2.9 and $8.4 \pm 3.5$ ) and was statistically significant affected compared to the control group (FMD=19.1 $\pm 11.0, \mathrm{p}<0.01$ ). (Figure $2 \&$ Table 2).

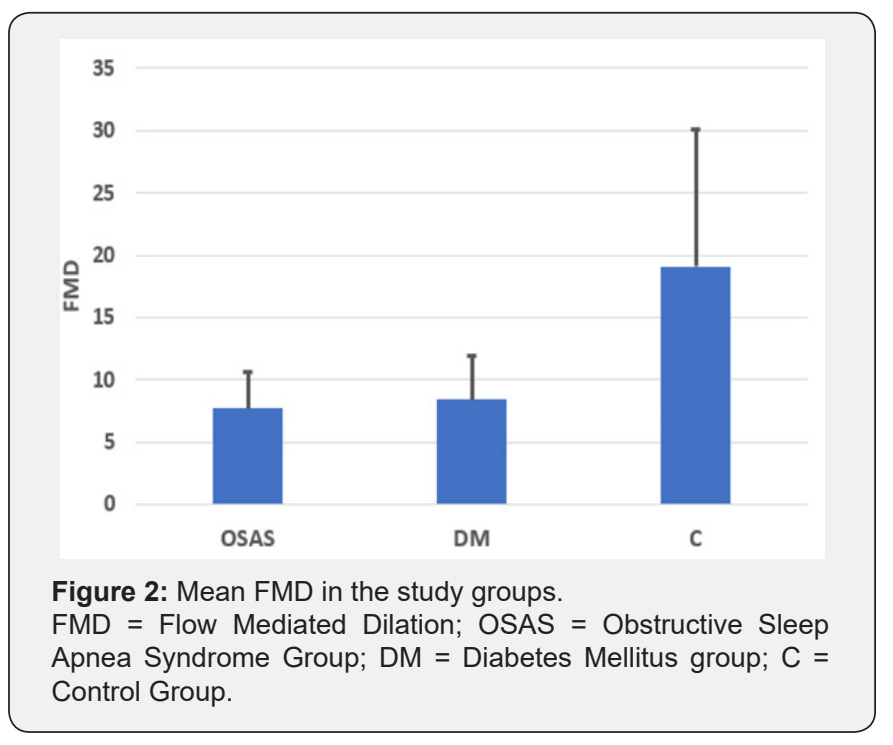

\section{Discussion}

We performed a comprehensive arterial function study in a group of patients with moderate-severe OSAS and type $2 \mathrm{DM}$ and we compared the results with control subjects. The main findings of our study define that patients with OSAS and DM have affected parameters of vascular remodeling, arterial stiffness, ventriculoarterial coupling, and endothelial function. Furthermore, the vascular profile of the patients with OSAS is similar to those with DM, suggesting that OSAS should be addressed as a risk factor for atherosclerosis.

The mechanisms of cardiovascular dysfunction in OSAS are not entirely elucidated. The sympathetic nervous system dysfunction, the endothelial dysfunction, systemic inflammation, oxidative stress, the negative intrathoracic pressure, obesity, and thrombosis have an important contribution to the cardiovascular dysfunction [11].
The present study brings into light a comprehensive practical approach of the vascular function assessment in patients with OSAS. Moreover, the protocol could be applied for other diseases, not only for patients with OSAS and DM, suggesting that the approach could validate a couple of parameters of tremendous importance for the arterial function assessment, not only the IMT, PWV and PP currently recommended by guidelines for the risk assessment of the hypertensive patients [12].

The IMT is increasingly used as a surrogate marker of atherosclerosis [4]. Higher IMT was reported in patients with sleep apnea, compared to control subject, in concordance with our findings [13].

According to a recent study, patients with OSAS have increased arterial stiffness, by reporting increased PVW and augmentation index and suggesting that there is a positive correlation between the gravity of the OSAS and the arterial stiffness [5].

A recent meta-analysis of 18 studies about arterial stiffness in OSAS patients, analyzing 736 patients with OSAS and 424 controls, reported increased arterial stiffness, increased endothelial dysfunction and high level of serum inflammatory markers in OSAS patients, compared to controls [14]. The arterial stiffness assessment protocol focused mainly on PWV and augmentation index. The ventricular-arterial coupling was studied in obstructive sleep apnea compared to high-risk arterial hypertension and the results were similar between groups and ameliorated by CPAP [15].

We have chosen to compare patients with OSAS with DM patients and controls, to point out the importance of OSAS, as a high-risk pathology, with high prevalence and responsible for the development of cardiovascular complications in this patient. The OSAS should not be considered as an isolated respiratory pathology, but an important high-risk pathology in the development of cardiovascular disease, comparable with DM [16].

\section{Conclusion}

Patients with moderate to severe OSAS have increased arterial remodeling, stiffness, and higher endothelial dysfunction, with similar vascular profile with patients with DM, when compared to control subjects. Our study offers an extensive protocol for the assessment of vascular function, that could be implemented in diagnosing early atherosclerosis. Further efforts should be invested in determining which therapeutically approach could improve the cardiovascular outcomes in these patients.

\section{References}

1. McNicholas WT, Bonsigore MR (2007) Sleep apnoea as an independent risk factor for cardiovascular disease: current evidence, basic mechanisms and research priorities. Eur Respir J 29(1): 156-178.

2. Tufik SB, Berro LF, Andersen ML, Tufik S (2015) Prevalence and classification of sleep-disordered breathing. Lancet Respir Med 3(4): 263-264.

3. Chung S, Yoon IY, Lee CH, Kim JW (2010) The association of nocturnal hypoxemia with arterial stiffness and endothelial dysfunction in male 
patients with obstructive sleep apnea syndrome. Respiration 79(5): 363-369.

4. Lorenz MW, Markus HS, Bots ML, Rosvall M, Sitzer M (2007) Prediction of clinical cardiovascular events with carotid intima-media thickness: a systematic review and meta-analysis. Circulation 115(4): 459-467.

5. Sarinc Ulasli S, Sariaydin M, Ozkececi G, Gunay E, Halici B, et al. (2016) Arterial stiffness in obstructive sleep apnoea: Is there a difference between daytime and night-time? Respirology 21(8): 1480-1485.

6. Zhou M, Guo B, Wang Y, Yan D, Lin C, et al. (2016) The Association Between Obstructive Sleep Apnea and Carotid Intima-Media Thickness: A Systematic Review and Meta-Analysis. Angiology 68(7): 575-583.

7. Bots ML, Sutton-Tyrrell K (2012) Lessons from the past and promises for the future for carotid intima-media thickness. J Am Coll Cardiol 60(17): 1599-1604.

8. Vinereanu D, Nicolaides E, Boden L, Payne N, Jones CJ, et al. (2003) Conduit arterial stiffness is associated with impaired left ventricular subendocardial function. Heart 89(4): 449-450.

9. Vinereanu D, Dulgheru R, Magda S, Dragoi Galrinho R, Florescu M, et al. (2014) The effect of indapamide versus hydrochlorothiazide on ventricular and arterial function in patients with hypertension and diabetes: results of a randomized trial. Am Heart J 168(4): 446-456.

10. Magda SL, Ciobanu AO, Florescu M, Vinereanu D (2013) Comparative reproducibility of the noninvasive ultrasound methods for the assessment of vascular function. Heart Vessels 28(2): 143-150.

This work is licensed under Creative Commons Attribution 4.0 License DOI: 10.19080/JOCCT.2019.13.555862
11. Magda SL, Mincu RI, Constantinescu T, Cinteza M (2014) Hipertensiunea ateriala si apneea obstructiva in somn. In: Publicis M, ed. Progrese in cardiologie 338-361.

12. Mancia G, Fagard R, Narkiewicz K, Redón J, Zanchetti A, et al. (2013) $2013 \mathrm{ESH} / \mathrm{ESC}$ Guidelines for the management of arterial hypertension: the Task Force for the management of arterial hypertension of the European Society of Hypertension (ESH) and of the European Society of Cardiology (ESC). J Hypertens 31(7): 1281-1357.

13. Levy P, Pepin JL, Arnaud C, Baguet JP, Dematteis M, et al. (2009) Obstructive sleep apnea and atherosclerosis. Prog Cardiovasc Dis 51(5): 400-410.

14. Wang J, Yu W, Gao M, Zhang F, Gu C, et al. (2015) Impact of Obstructive Sleep Apnea Syndrome on Endothelial Function, Arterial Stiffening, and Serum Inflammatory Markers: An Updated Meta-analysis and Metaregression of 18 Studies. J Am Heart Assoc 4(11).

15. Shantsila A, Shantsila E, Butt M, Khair OA, Dwivedi G, et al. (2014) Ventricular-arterial coupling in obstructive sleep apnea. J Am Soc Hypertens 8(9): 624-629.

16. Low Wang CC, Hess CN, Hiatt WR, Goldfine AB (2016) Clinical Update: Cardiovascular Disease in Diabetes Mellitus: Atherosclerotic Cardiovascular Disease and Heart Failure in Type 2 Diabetes Mellitus - Mechanisms, Management, and Clinical Considerations. Circulation 133(24): 2459-2502.

\begin{tabular}{l} 
Your next Submission with Juniper Publishers \\
will reach you the below assets \\
- Quality Editorial service \\
- Swift Peer Review \\
- Reprints availability \\
- E-prints Service \\
- Manuscript Podcast for convenient understanding \\
- Global attainment for your research \\
- Manuscript accessibility in different formats \\
( Pdf, E-pub, Full Text, Audio) \\
- Unceasing customer service \\
Track the below URL for one-step submission \\
https://juniperpublishers.com/online-submission.php \\
\hline
\end{tabular}

